\title{
Dos pinturas inéditas de Rodríguez de Losada
}

\author{
Álvaro Cabezas García \\ Universidad de Sevilla \\ alvarocabezasgarcia@gmail.com
}

En un domicilio particular de la población sevillana de Tomares, se conservan dos pinturas hasta ahora inéditas y firmadas por José María Rodríguez de los Ríos y de Losada (Sevilla, 20 de julio de 1826-Jerez de la Frontera, 2 de abril de 1896) ${ }^{1}$. En los últimos años está siendo frecuente el descubrimiento de nuevas de sus pinturas y dibujos en colecciones privadas y en catálogos de casas de subastas².

Esta circunstancia no debe resultar extraña, ya que se trata de un autor de copiosa y aun poco tratada producción, que merece alguna reflexión y puesta en valor, sobre todo en relación a un aspecto relativamente desconocido que concierne a la autorreferencia estética de la Escuela de pintura sevillana. Me estoy refiriendo, naturalmente, a la deuda contraída por artistas como este con los grandes maestros del pasado, sobre todo con Bartolomé Esteban Murillo (Sevilla, diciembre de 1617-3 de abril de 1682), precursor de la pintura costumbrista sevillana (Reina, 1979: 45). No obstante, Rodríguez de Losada se formó, como la mayoría de los pintores de su época, bajo el influjo de Murillo mantenido vivo, y en ascenso, no solo gracias a la Escuela provincial de Bellas Artes, sino también a la literatura de viajes que emanó de los muchos visitantes extranjeros que tuvo la Sevilla decimonónica (Alberich, 2000). Pero, además de esto, fue uno de los autores que lo hizo figurar en determinados cuadros con intención de historiar su vida. Prueba de ello son sus lienzos Murillo copiando el grupo de Santa Isabel por el modelo y Murillo tras la caída en la iglesia de Capuchinos de Cádiz. Pero, como muy bien expresa Valdivieso, Rodríguez de Losada fue «un testimonio elocuente de la versatilidad acomodaticia a las modas y las tendencias comerciales" (19862002: 427), por lo que, igual que se mostró como perfecto traductor del murillismo, también manifestó su admiración por una tendencia pretendidamente contraria: la de Juan de Valdés Leal (Sevilla, 4 de mayo de 1622-15 de octubre de
1690), a quien pintó en la obra $D$. Juan Valdés Leal, inspirándose en un panteón para pintar el cuadro que se conserva en la iglesia de la Caridad de Sevilla (premiada en la Exposición de Cádiz de 1854 y en la Nacional de 1858)3. Por ello, el estudio de la pintura religiosa de Rodríguez de Losada es tan necesario: es idóneo medidor de los síntomas estéticos que pueden contribuir a la mejor comprensión de la sensibilidad religiosa de raíz burguesa por parte de los elementos más predominantes y conspicuos de sociedades ciertamente conservadoras como las que encargaban pintura para lo privado, en Sevilla o Jerez, fuera de los criterios oficiales que regían, por entonces, los certámenes de obras a los que concurrió con asiduidad, cosechando importantes éxitos con el género representativo de la época: la pintura de Historia. Este tipo de pintura fue enormemente contestado en las décadas siguientes por parte de los propios artistas ${ }^{4}$, no solo por ser el mecanismo con el que el Estado, a través de sus recientemente inauguradas terminales artísticas provinciales, trabajó para fijar y delimitar bien los momentos de la Historia española que debían ser recordados, sino también el gusto artístico. Este estado de cosas provocó que quedaran al margen de la oficialidad determinados talentos que no quisieron o pudieron adaptarse, o quizá, precisamente, por ajustarse a las normas establecidas, perdieron gran parte de su personalidad y aportaciones individuales.

Las pinturas que se dan a conocer en este estudio resultan de encargos particulares motivados por destacadas familias sevillanas que, en los comedios del siglo XIX, querían adornar sus residencias con asuntos alusivos a la función doméstica -un comedor, un oratorio o capilla privada-, siempre que fueran estéticamente admirables, y sobre todo si, como es el caso, los cuadros entroncaban a la perfección con la hermosura tradicional de la escuela de pintura local. Suponen un ejemplo destacado de la versatilidad menciona- 


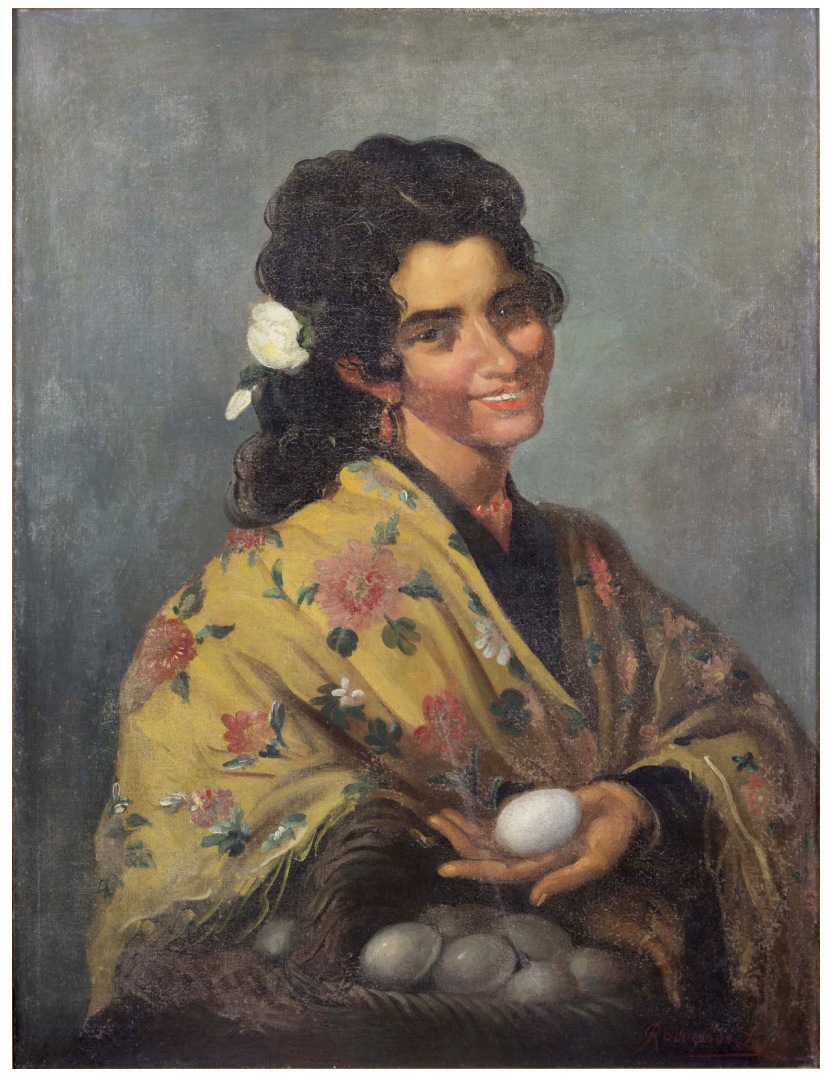

1. José María Rodríguez de Losada, La recovera, óleo sobre lienzo. Colección particular, Tomares

da que disfrutó Rodríguez de Losada en su carrera artística, ya que una de ellas podría encuadrarse dentro de su primera etapa y otra en su periodo postrero. Se conoce perfectamente cómo este pintor, no solo ejecutaba sus obras con enorme rapidez, sino que pudo dominar y ser reconocido por destacar en géneros pictóricos distintos, algo que le valió para alcanzar una posición preponderante en los círculos

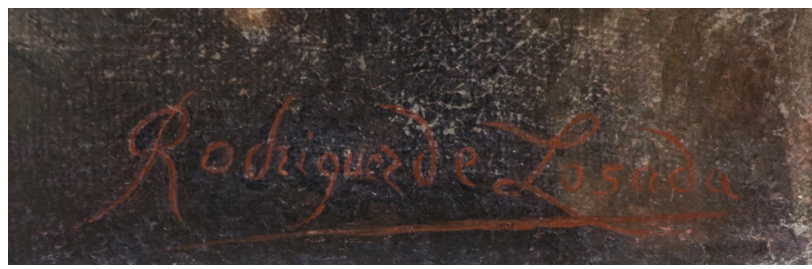

2. José María Rodríguez de Losada, La recovera (detalle de la firma), óleo sobre lienzo. Colección particular, Tomares intelectuales de su tiempo. Por consiguiente, Rodríguez de Losada tenía una verdadera noción de importancia y responsabilidad sobre sí mismo, ya que se consideraba el último eslabón de una áulica cadena artística que se mantenía con su pintura, pero que debía continuar para las generaciones futuras. Algo de todo lo anterior, puede encontrarse en las pinturas que aquí se estudian por primera vez.

La primera de ellas podría titularse la Recovera [1] (óleo sobre lienzo, 85,5 x 65 cm y firmado en el ángulo inferior derecho en color rojo como «Rodriguez de Losada» [2]). Muestra una joven de cintura para arriba, de cabello negro y ondulado, recogido ampliamente por detrás y adornado con una flor blanca. Mira al espectador sonriente y ofreciendo con su mano izquierda un huevo blanco que ha extraído de la cesta que carga con el brazo contrario y que contiene más de media docena de ellos. La encarnadura de la mujer es viva, especialmente en los pómulos rosados, símbolo, no solo de alegría, sino de lozanía y buena salud. Aparece ataviada con un bello mantón de Manila de color amarillo con flores de distintos tamaños y formas, pero siempre de color rojizo. No solo este destacado elemento -verdadero reclamo del cuadro-, sino los bermellones labios, pendientes y cuentas del collar que adorna su cuello, otorgan a la figura un sentido de prestancia y dignidad muy alejado del naturalismo pretendido por otros autores costumbristas que deseaban ofrecer una imagen fidedigna de la realidad con detalles, a veces, crudos y escabrosos. Más bien la opción escogida aquí por Rodríguez de Losada será la acometida en Sevilla años más tarde por Manuel Ussel de Guimbarda (Trinidad de Cuba, 26 de noviembre de 1833-Cartagena, 9 de mayo de 1907), o Joaquín Turina y Areal (Sevilla, 184724 de noviembre de 1903), pero de forma menos seca que esta obra temprana de Rodríguez de Losada. Un pintor ya de la centuria siguiente, Alfonso Grosso Sánchez (Sevilla, 1 de septiembre de 1893-9 de diciembre de 1983), codificará la abierta sonrisa ensayada aquí por Rodríguez de Losada con su recurrente «sonrisa-elixir» en las pinturas dedicadas al tipismo sevillano ${ }^{5}$.

La otra pintura es un San Francisco [3] (óleo sobre lienzo, 104 x 72,5 cm), firmado en el ángulo inferior izquierdo en negro como «Rodrigz. de Losada» [4]. Ofrece una impronta muy distinta a la de la pintura anterior, a causa, primordialmente, de los rasgos que muestran mayor dominio del color y madurez en la pincelada del autor, por lo que 
podría incluirse en su última etapa. Si bien La recovera se mostraba más plana, esta pintura del santo de Asís destila una mayor trascendencia y unción religiosa, sobre todo a partir, de la gradación de colores pardos y grises, a través de los que puede hacerse un recorrido desde el tono más oscuro del terrado, al del hábito del santo y la calavera, hasta llegar al pálido por el que deja entreverse un cielo nublado y solo, y parcialmente, interrumpido por unos rayos solares que indican la presencia divina en el ángulo superior izquierdo, justo sobre una cruz de palo, que se proyectan sobre el rostro del orante. La composición es solemne: San Francisco está en la Porciúncula, arrodillado delante de un saliente de roca sobre el que está colocada la cruz, y reza imbuido del hálito de Dios con las manos unidas y el rostro clavado en el cielo. El autor consigue con esta figuración algunos detalles de enorme calidad: las uñas largas, la barba picuda y blonda que nace casi imperceptiblemente de los pómulos, la llaga de los clavos que solo se adivina en la mano izquierda, los ojos enrojecidos, la oreja perfecta, la nariz prominente, etc. Mención aparte merece la extraordinaria ejecución de la túnica del santo, llena de pliegues en la capucha y en las mangas, donde estos alcanzan cotas de virtuosismo con su reminiscencia zurbaranesca. Precisamente en estas zonas es donde se aprecian los barnices más estropeados. Es importante señalar, por tanto, que tras la contemplación de pinturas de asuntos como este, habría que revisar la consideración de Valdivieso cuando afirma que Rodríguez de Losada tiene "escasa convicción con respecto a las devociones representadas» (1981: 96), ya que esta muestra una perfecta traducción de la estética barroca a la piedad más íntima y sentimental que demandaban las clases acomodadas de Andalucía occidental a mediados del siglo XIX. Así lo ponen de manifiesto las soluciones valdesianas tomadas, por ejemplo, del Santiago de La Inmaculada Concepción con Felipe y Santiago (París, Museo del Louvre), e incluso del San Jerónimo protagonista del lienzo de Las tentaciones de San Jerónimo (Sevilla, Museo de Bellas Artes).

Conociendo obras como estas, alcanza todo su significado el juicio de Pérez: la obra artística de Rodríguez de Losada supone una síntesis barroca-romántica (2004: 424), que ayuda mucho a la comprensión de los procesos y prácticas religiosas de una etapa tan compleja como la ocurrida en España durante el siglo XIX.

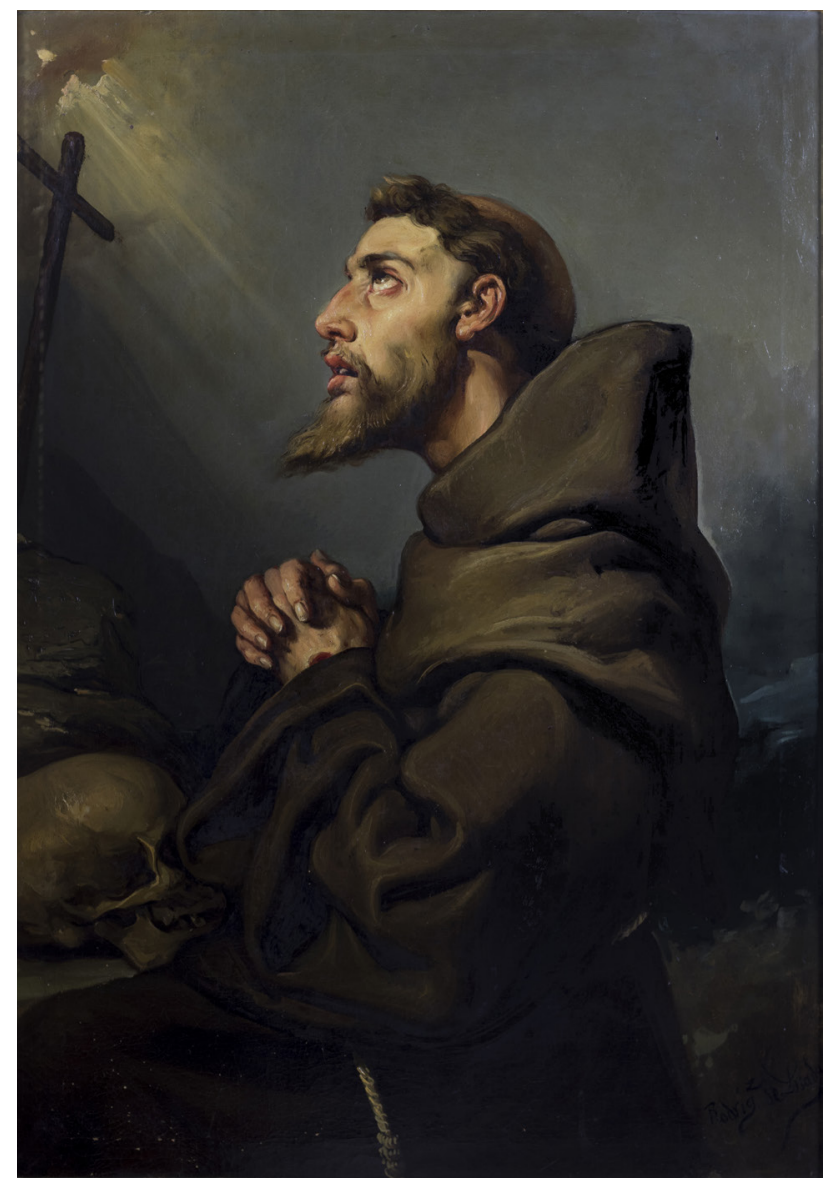

3. José María Rodríguez de Losada, San Francisco de Asís, óleo sobre lienzo. Colección particular, Tomares

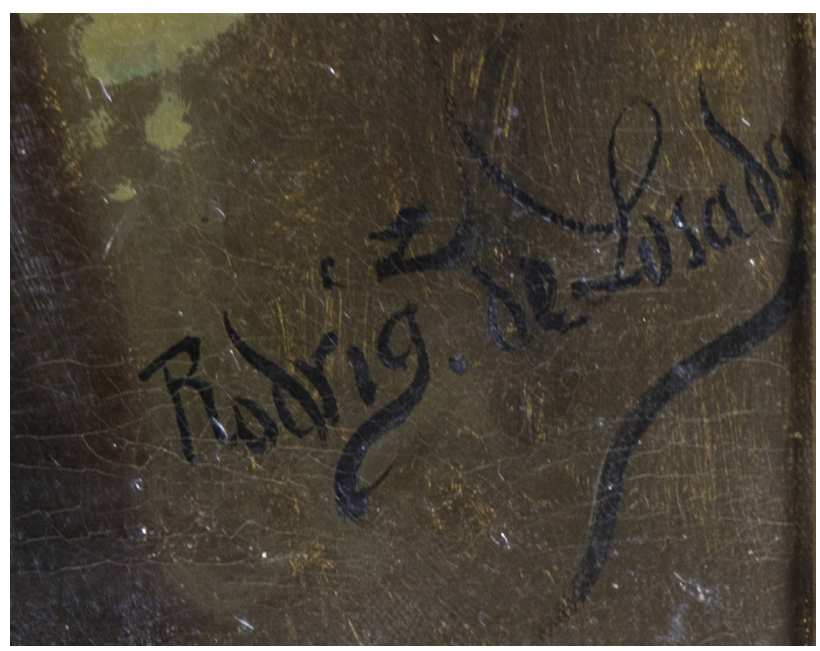

4. José María Rodríguez de Losada, San Francisco de Asís (detalle de la firma), óleo sobre lienzo. Colección particular, Tomares 


\section{Notas}

1 Los primeros juicios emitidos sobre este pintor fueron los de Ossorio (1883-1884-1975: 589); Méndez (1922); y Cuenca (1923: 319). Con posterioridad, fue estudiado convenientemente por Valdivieso (1981: 96-98); y Valdivieso (1986-2002: 417 y 418). A partir de ahí, fue objeto de diversas publicaciones, tratándolo algunas desde el plano local, sobre todo desde Jerez de la Frontera: Banda (1996: 90-91); Caballero (2003: 191-198); Pérez (2004: 417-430); y Romero (2005). También aparece en catálogos y estudios recopilatorios como los de Palomo (1998: 32-36); y Caballero (238-254). En los últimos años fueron añadidas algunas pinturas a su catálogo: Cabezas (2015).

2 Pérez, 2004: 418, daba cuenta de un Crucificado subastado en 1995, pero en la primavera de 2015 no menos de cinco casas de subastas -entre las que se encontraban Segre y Artnet-, anunciaban la venta por Internet de obras de Rodríguez de Losada, casi todas de asunto religioso. La última de estas ventas tuvo lugar el 30 de enero de 2018 por parte de Isbilya, en Sevilla. Con el n. ${ }^{\circ}$ 208, figuraba en el catálogo de la subasta un Retrato de árabe firmado por el pintor teniendo como medidas $47 \times 35 \mathrm{~cm}$.

3 Reproducida en Valdivieso, 1981, fig. 14.

4 Este género llenó de «esperpentos toda la pintura española y los salones y los Museos de aquella época», en opinión de Grosso (1939: 9).

5 Sobre Turina escribió Valdivieso, 1981: 133; sobre la «sonrisa-elixir» de Grosso escribió Hurtado, 1994-1995: 17.

\section{Bibliografía}

ALBERICH, José (2000), Del Támesis al Guadalquivir. Antología de viajeros ingleses en la Sevilla del siglo XIX, Universidad de Sevilla, Sevilla. BANDA Y VARGAS, Antonio de la (1996), «La pintura jerezana en el siglo XIX», Archivo Español de Arte, n. ${ }^{\circ}$ 273, pp. 85-96.

CABALLERO RAGEL, Jesús (2003), «El pintor José María Rodríguez Losada (Sevilla, 1826-Jerez 1896», Revista de Historia de Jerez, n. ${ }^{\circ}$ 9, pp. 191-198.

CABALLERO RAGEL, Jesús, Exposiciones y artistas en el Jerez del XIX: las exposiciones de la Sociedad Económica Jerezana, Ayuntamiento de Jerez, Jerez.

CABEZAS GARCÍA, Álvaro (2015), «Un nuevo crucificado de José María Rodríguez de Losada en una comunidad religiosa sevillana», Boletín de arte, n. ${ }^{\circ} 36$, pp. 209-212.

CUENCA, Francisco (1923), Museo de pintores y escultores andaluces contemporáneos, La Habana.

GROSSO, Alfonso (1939), Conferencia en homenaje a la memoria del insigne pintor sevillano Gonzalo Bilbao, Imprenta Provincial, Sevilla. HURTADO MARJALIZO, María Eugenia (1994-1995): «Grosso, la última tipificación del realismo sevillano» en Alfonso Grosso. Exposición Conmemorativa del Centenario de su nacimiento, Museo de Bellas Artes de Sevilla, Sevilla, pp. 17-27.

MÉNDEZ CASAL, Antonio (1922), «El pintor Losada», Revista Raza Española, n. 41, pp. 47-72.

OSSORIO Y BERNARD, Manuel (1883-1884-1975), Galería biográfica de artistas españoles del siglo XIX, Giner, Madrid.

PALOMO, Bernardo (1998), La pintura en Jerez: revisión histórica, Ayuntamiento de Jerez, Jerez.

PÉREZ CALERO, Gerardo (2004), «El pintor José María Rodríguez de Losada (1826-1896) y la Orden de Caballería del Santo Sepulcro», en Actas de las IV Jornadas de Estudio La Orden del Santo Sepulcro, Centro de Estudios de la Orden del Santo Sepulcro, Zaragoza, Calatayud, pp. 417-430.

REINA PALAZÓN, Antonio (1979), La pintura costumbrista en Sevilla (1830-1870), Universidad de Sevilla, Sevilla.

ROMERO COLOMA, Aurelia María (2005), Aproximación al estudio de la personalidad artística de José María Rodríguez de Losada, la autora.

VALDIVIESO, Enrique (1981), Pintura sevillana del siglo XIX, el autor, Sevilla.

- (1986-2002), Historia de la pintura sevillana, siglos XIII al XX, Guadalquivir Ediciones, Sevilla. 